\title{
Can Lextale-Esp discriminate between groups of highly proficient Catalan-Spanish bilinguals with different language dominances?
}

\author{
Pilar Ferré $^{1} \cdot$ Marc Brysbaert ${ }^{2}$
}

Published online: 22 March 2016

(C) Psychonomic Society, Inc. 2016

\begin{abstract}
Researchers have recently introduced various LexTALE-type word recognition tests in order to assess vocabulary size in a second language (L2) mastered by participants. These tests correlate well with other measures of language proficiency in unbalanced bilinguals whose second language ability is well below the level of their native language. In the present study, we investigated whether LexTALE-type tests also discriminate at the high end of the proficiency range. In several regions of Spain, people speak both the regional language (e.g., Catalan or Basque) and Spanish to very high degrees. Still, because of their living circumstances, some consider themselves as either Spanish-dominant or regionallanguage dominant. We showed that these two groups perform differently on the recently published Spanish Lextale-Esp: The Spanish-dominant group had significantly higher scores than the Catalan-dominant group. We also showed that the noncognate words of the test have the highest discrimination power. This indicates that the existing Lextale-Esp can be used to estimate proficiency differences in highly proficient bilinguals with Spanish as an L2, and that a more sensitive test could be built by replacing the cognates.
\end{abstract}

Keywords LEXTALE_Esp · Vocabulary size $\cdot$ Language proficiency $\cdot$ Bilingualism

Pilar Ferré

mariadelpilar.ferre@urv.cat

1 Research Center for Behavior Assessment and Department of Psychology, Rovira i Virgili University, Tarragona, Spain

2 Ghent University, Ghent, Belgium
Proficiency has a central role in research on bilingualism (Lemhöfer \& Broersma, 2012). Indeed, the second language (L2) proficiency has been demonstrated to affect performance in a variety of experimental tasks and paradigms. Davis et al. (2010), for instance, observed that highly proficient bilinguals show an interlingual cognate priming effect of the same magnitude as a within-language repetition effect (e.g., for an English-Spanish bilingual, there is as much priming for the prime-target pair rico-RICH as for the pair rich-RICH). The same was not true for beginning bilinguals, when the prime was in L2 and the target in the first language (L1). Rossi, Gugler, Friederici, and Hahne (2006) reported that highly proficient late L2 learners showed the same event-related potential responses to syntactic violations in sentences as L1 speakers, but this was not true for low-proficiency L2 learners, who had a qualitatively different response to the violations. Other neuroscientific research has indicated that the pattern of brain activation is modulated by L2 proficiency. Whereas highly proficient L2 speakers activate the same brain areas as L1 speakers during lexico-semantic processing in the L2, less proficient bilinguals show the engagement of additional brain areas when performing tasks in the L2 (see Abutalebi, 2008, and Costa \& Sebastián-Gallés, 2014, for reviews). Finally, Prior, MacWhinney, and Kroll (2007) reported that less proficient bilinguals produce lower-probability translations from L1 to L2 than do more proficient bilinguals.

Taking all of the above into account, it is clear that researchers should measure participants' proficiency levels in all bilingual studies, not just in those directly addressing the issue of proficiency levels. Unfortunately, this is rarely done with much precision (Lemhöfer \& Broersma, 2012). A common approach is to use self-ratings (i.e., participants are asked to rate their own proficiency levels on a Likert scale).

Although self-ratings are a useful source of information, they suffer from several shortcomings. One is that they may 
not be comparable across studies (Brysbaert, 2013). For instance, Lemhöfer and Broersma (2012) reported differences between Dutch-English bilinguals and Korean-English bilinguals in the extent to which subjective proficiency assessments correlated with performance in translation tasks, as well as with a test for general proficiency. This difference might have been due to cultural differences. Studies may also differ in other aspects. For instance, L2 speakers might give themselves higher ratings in a paid than in an unpaid experiment, since there is more to be earned in the former.

A second shortcoming of self-ratings is that they are influenced by individual differences. MacIntyre, Noels, and Clément (1997), for instance, reported that L2 self-ratings were influenced as much by language anxiety as by language proficiency. Language anxiety was measured with a questionnaire asking how anxious participants felt using their L2 in a variety of circumstances; proficiency was measured with a series of language production tasks. The authors found that participants with low anxiety overestimated their proficiency level, whereas participants with high anxiety underestimated their performance. Similarly, Izura, Cuetos, and Brysbaert (2014) observed that L2 speakers in general have lower performance levels than L1 speakers with the same self-ratings. Arguably this is because the two groups use different criteria: L2 speakers compare themselves to other L2 speakers, whereas L1 speakers compare themselves to other L1 speakers.

A final limitation of self-ratings is that they tend to give rather crude information. For instance, Izura et al. (2014) found that low and high ratings were good indications of, respectively, poor and strong performance, but that medium ratings ( $4-8$ on a 10 -point scale) were associated with a large variety of performance levels. Along the same lines, participants might be perfectly able to indicate that they are more dominant in one language than in the other, but this is rather limited information if one wants to use language proficiency as a predictor variable or to estimate the difference in proficiency levels between the languages.

In light of the limitations above, there is a great need for performance-based measures of language proficiency with good sensitivity and specificity. Several measures have been proposed. For instance, some researchers have relied on fluency tasks (e.g., Ferré, García, Fraga, Sánchez-Casas, \& Molero, 2010), others on vocabulary tests (e.g., Conrad, Recio, \& Jacobs, 2011), and still others on commercially available proficiency tests (e.g., Zhou, Chen, Yang, \& Dunlap, 2010). Common problems with these tests are that they are too demanding (in time or technical facilities) and/ or too expensive.

Lemhöfer and Broersma (2012) proposed a quick and easy way to measure L2 proficiency, which can be used with different groups of bilinguals. It relies on word knowledge as a proxy for language proficiency and is called the Lexical Test for Advanced Learners of English (LexTALE). The test consists of an unspeeded lexical decision task in which participants have to make word/nonword decisions to 60 items (40 words and 20 nonwords). The list includes words ranging from moderately well-known to very well-known to native speakers. In this way, various proficiency levels can be discerned in L2 speakers. Nonwords are included to correct the test for false positives (i.e., the tendency that some participants have to indicate that they "know" words they have never encountered before). The number of nonwords is smaller than the number of words to make the subjective proportions of words and nonwords more equal, given that most participants do not know all the words. The final score is computed by taking into account both the number of correct words identified and the "yes" responses to nonwords.

Lemhöfer and Broersma (2012) validated LexTALE by examining its relationship with other measures of L2 proficiency in a group of Korean-English bilinguals and a group of Dutch-English bilinguals. The participants not only took LexTALE, but also completed a translation task, which was performed in both translation directions (from L1 to L2, and the other way around), and a test for general English proficiency (the Quick Placement Test, QPT; University of Cambridge, Local Examinations Syndicate, 2001). Finally, they also rated their English proficiencies in reading, writing, speaking, and listening. Lemhöfer and Broersma examined which measure (i.e., LexTALE scores or subjective proficiency ratings) was more correlated with the objective measures (i.e., the QPT scores and the translation performance). The results revealed that LexTALE scores correlated substantially higher than self-ratings with QPT and translation performance. To obtain further evidence of the predictive value of LexTALE, Lemhöfer and Broersma reanalyzed the data of two previous studies (Lemhöfer \& Dijkstra, 2004; Lemhöfer et al., 2008), in which bilinguals had participated in two different experimental paradigms commonly used in word recognition studies: lexical decision and progressive demasking. Participants had also completed self-ratings of proficiency together with LexTALE. The results showed that the LexTALE scores were more correlated to the experimental measures (i.e., reaction times and error rates) than were the self-ratings. In light of these findings, Lemhöfer and Broersma concluded that LexTALE provides a valid and useful measure of the English vocabulary knowledge of bilinguals with different proficiency levels, who have English as a second language.

Since the publication of Lemhöfer and Broersma's (2012) article, other researchers have reported evidence regarding the usefulness of LexTALE. For instance, Diependaele, Lemhöfer, and Brysbaert (2013) demonstrated that participants with low LexTALE scores had steeper word frequency effects in visual word recognition than did participants with high scores. Interestingly, the results of this study also revealed that the larger word frequency effect in L2 than is usually found in L1 could be accounted for by differences in 
vocabulary size. In other work, Khare, Verma, Kar, Srinivasan, and Brysbaert (2013) focused on the attentional blink effect (i.e., the difficulty reporting a second visually presented target when it appears in close proximity to a first visual target; Raymond, Shapiro, \& Arnell, 1992). These researchers obtained a significant positive correlation between the attentional blink effect and bilinguals' proficiency in the L2. That is, bilinguals showed a stronger attentional blink effect than did monolinguals. Importantly, the correlation was only reliable when LexTALE scores were used, not when participants' self-ratings were considered, again suggesting that performance-based assessment of L2 proficiency is more informative than subjective ratings.

Other researchers have used LexTALE to assess bilinguals' proficiency in their first as well as in their second language (e.g., Bultena, Dijkstra, \& van Hell, 2014; Cop, Keuleers, Drieghe, \& Duyck, 2015; Correia et al., 2014; De Bruin, Roelofs, Dijkstra, \& FitzPatrick, 2014; Weber, Broersma, \& Aoyagi, 2011), or to assess the L2 proficiency levels of different groups of bilinguals included in the same study (Christoffels, de Haan, Steenbergen, van den Wildenberg, \& Colzato, 2014). The results of these studies confirmed that participants differing in LexTALE scores also show differences in performance in linguistic tasks. For instance, Cop et al. (2015) observed that the frequency effect in natural reading decreased with increasing L1 proficiency as measured by LexTALE. Christoffels et al. reported that LexTALE scores are also useful in research on nonlinguistic tasks. They found differences in cognitive flexibility between bilinguals who followed regular classes in the L2 and those who did not. Of note, the former had higher LexTALE scores than the latter.

On the basis of the work of Lemhöfer and Broersma (2012), LexTALE-type tests have also been developed for other languages. First, Lemhöfer and Broersma developed LexTALE versions for Dutch and German, which were matched to the English test to make cross-language comparisons possible (see www.lextale.com). Second, Brysbaert (2013) and Izura et al. (2014) published LexTALE-inspired tests for French and Spanish (respectively named Lextale-Fr and Lextale-Esp). These tests differed in a number of respects from the original LexTALE, the most important of which is that no attempt was made to equate the difficulty levels of the words cross-linguistically, so that the scores can no longer be compared across languages. ${ }^{1}$ Both Brysbaert and Izura et al. were more interested in developing a test that could be used across a wide range of proficiency levels, including native speakers. Therefore, their tests included more difficult items. The authors were also more lenient in the administration of the test. Whereas the original

\footnotetext{
${ }^{1}$ Another, better way to compare scores across languages would be to present the various tests to comparable groups of native speakers (e.g., ungraduated students), so that standardized scores could be calculated on the basis of the norms.
}

LexTALE tests must be taken online with a yes/no response given to each individual word, the new tests were also administered on paper. Participants got a sheet of words and nonwords and were asked to mark all the words they knew. Because of these differences, it is better not to denote the new tests with the original name LexTALE, but with the acronym Lextale-*, in which Lextale still stands for a lexical test for advanced learners, and the suffix indicates which language is being tested. Lextale-Fr was recently used successfully as a measure of spelling ability and vocabulary of native French speakers (Beyersmann, Casalis, Ziegler, \& Grainger, 2015), indicating that it can be used to assess L1 abilities.

The construction of the Spanish Lextale-Esp test was inspired by Brysbaert (2013). Izura et al. (2014) selected an original pool of 90 words, ranging in frequency from very high to very low, and a set of 90 nonwords. The authors presented these items to a group of highly proficient Spanish L1 speakers and to a group of Spanish L2 speakers with different L1 backgrounds. On the basis of point-biserial correlations between the responses to the items and the participants' total scores, and of an item response theory analysis, they selected the 60 best words and the 30 best nonwords to assess Spanish proficiency, from very low to very high, and included them in the final version of Lextale-Esp. Concerning the differences between groups, the results obtained with Lextale-Esp were similar to those obtained with Lextale-Fr (Brysbaert, 2013). Indeed, the difference in performance between the Spanish L1 speakers and the low-proficiency Spanish L2 speakers in Izura et al.'s study was huge (i.e., the average scores for the L1 group and the L2 group were 53.9 and 11.9, respectively, out of a total of 60 , corresponding to a standardized effect size of $d=3.1$ ), demonstrating the discrimination power of the test.

A considerable line of bilingualism research in Spain, however, is not directed at differences between native speakers and unbalanced bilinguals with rather low levels of Spanish knowledge. An interesting feature of the Spanish society is that in various regions, local languages are spoken in addition to Spanish. One of these regions is Catalonia, where both Catalan and Spanish are official languages. In Catalonia, people usually are highly proficient in both Catalan and Spanish. Some people are raised bilingually (i.e., with mixed-language parents), and everybody learns both languages in an immersion context from early childhood. This type of population is rather uncommon in bilingualism research, in which the participants often are substantially more proficient in L1 than in L2. It provides us with a unique population that comes closest to the ideal of balanced bilinguals. This is interesting for exploring various research questions (see, e.g., Costa \& Santesteban, 2004; Duñabeitia, Perea, \& Carreiras, 2010). Even in this population, however, most individuals differ in the degrees to which they use Spanish and Catalan in daily life, and therefore have a dominant language. This can be assessed through questionnaires that include questions on 
language use and preference (Moldovan, Sánchez-Casas, Demestre, \& Ferré, 2012; see also below). Given the limitations of subjective assessments described above, it would be interesting to know whether Lextale-Esp scores can be used in this population as a performance-based measure of proficiency in Spanish.

In the present study, we compared Catalan students, who were all highly proficient in Spanish, but who considered themselves as either Spanish-dominant or Catalan-dominant in a language history questionnaire. In addition, we compared their performances on cognate and noncognate words. Because Catalan and Spanish are closely related languages, many words have the same origin and, therefore, are cognates (words with the same meaning and a similar form). Izura et al. (2014) were aware of this problem, but decided not to take cognate status into account, because this would have made the test rather artificial, because Spanish has cognates with many languages (Basque, Catalan, English, French, Italian, Portuguese, ....).

\section{Method}

\section{Participants}

An initial pool of 184 students in the Education Department at Rovira i Virgili University (Tarragona, Spain) participated as volunteers in the study. All of them were highly proficient bilinguals of Catalan and Spanish. The participants were classified as Catalan-dominant or Spanish-dominant on the basis of their answers to a language history questionnaire in which they had to assess their competences in listening, reading, speaking, and writing in Catalan and Spanish on a 7-point scale $(1=$ a very poor level of competence, $7=$ a very good level). They also rated their frequency of language use for each of the four abilities on a 7-point scale $(1=$ only in Catalan, $7=$ only in Spanish), and also their preferences of use for the four abilities $(1=$ only in Catalan, $7=$ only in Spanish $)$. We obtained global scores for proficiency, frequency, and preference by averaging the data of the four abilities. Participants were considered as Spanish-dominants when their average proficiency level was higher in Spanish than in Catalan and when their average frequency and preference of use were higher than 4 on the 1 to 7 scale. Conversely, they were classified as Catalan-dominants if their average proficiency level was higher in Catalan than in Spanish and their average frequency and preference of use were equal to or lower than 4 . We discarded 26 bilinguals who could not be clearly classified as dominant in one of the two languages. This classification led to a final group of 156 participants (134 women, 22 men; ages ranging from 17 to 36 years, $M_{\text {age }}=20.8, S D=3.3$ ), composed of 86 Catalan-dominants and 70 Spanishdominants (see Table 1).

\section{Materials}

Lextale-Esp consists of 60 Spanish words and 30 nonwords. To explore the effects of cognate status, we classified the 60 Spanish words as cognates or noncognates. To that end, we used the NIM engine (Guasch, Boada, Ferré, \& SánchezCasas, 2013) to compute the degree of orthographic similarity (Van Orden, 1987) as well as the normalized Levensthein distance (Levensthein, 1966) between the Spanish words and their Catalan translation equivalents. Both parameters range from 0 to 1 , where 1 means a total overlap in orthography between the two words and 0 means no overlap at all. We considered a given word a cognate if either of the two parameters was higher than .5. According to this criterion, Lextale-Esp includes 39 cognate words and 21 noncognate words between Catalan and Spanish.

In addition to the Lextale-Esp, participants filled in the language history questionnaire described above, developed by our research group. It contains questions about proficiency, frequency of use, and preference of use for the two.

\section{Procedure}

Participants completed the paper-and-pencil version of Lextale-Esp (Izura et al., 2014) during a classroom session. This version includes 90 strings of letters. The instructions were taken from Izura et al. (2014). Participants were asked to indicate the Spanish words they knew by ticking the box next to them. They were also warned against guessing, because errors were penalized. There was no time limit. When they were finished, participants filled in a paper-and-pencil version of the language history questionnaire.

\section{Results}

The global test score of Lextale-Esp in the present study was the same as for that used by Izura et al. (2014). It was defined as:

Score $=N_{\text {yes to words }}-2 * N_{\text {yes to nonwords }}$.

We also computed the percentages of cognate and noncognate words identified by the participants, as well as an index of the cognate advantage (i.e., the percentage of correctly identified cognates minus the percentage of correctly identified noncognates).

The results are represented in Table 1. We would first note that the score of our Spanish-dominant group was very close to that obtained by Izura et al. (2014) with native speakers of Spanish $(M=53.2, S D=5.6$, as compared to $M=53.9, S D=$ 6.6). Thus, our Spanish-dominant bilinguals are very similar to the population for which the test was developed. 
Table 1 Data from the language history questionnaire and Lextale_Esp scores of Catalan-dominant and Spanish-dominant bilinguals (standard deviations in parentheses)

\begin{tabular}{lll}
\hline & Spanish-Dominant Bilinguals & Catalan-Dominant Bilinguals \\
\hline Spanish proficiency & $6.6(0.4)$ & $6.3(0.7)^{*}$ \\
Catalan proficiency & $6.0(0.9)$ & $6.7(0.4)^{*}$ \\
Preference of use & $5.5(0.9)$ & $2.5(1.0)^{*}$ \\
Frequency of use & $5.4(0.8)$ & $2.5(0.8)^{*}$ \\
Lextale-Esp words & $56.6(4.3)$ & $52.9(5.7)^{*}$ \\
Lextale-Esp nonwords & $1.7(2.1)$ & $2.0(2.6)$ \\
Lextale-Esp total score & $53.2(5.6)$ & $48.9(7.1)^{*}$ \\
Percentage of cognates recognized & $96.0(5.2)$ & $91.8(7.9)^{*}$ \\
Percentage of noncognates recognized & $90.8(11.7)$ & $81.6(14.5)^{*}$ \\
Cognate advantage & $5.2(7.9)$ & $10.2(10.1)^{*}$ \\
\hline
\end{tabular}

${ }^{*} p<.001$

We next analyzed the correlations between the total Lextale-Esp scores and the self-assessment ratings included in the language history questionnaire (see Table 2). Because we had many comparisons, the critical $p$ value was divided by the number of comparisons (Bonferroni correction). Hence, a correlation was significant only if $p<.003$. When we included all the participants in the analysis, we found a significant correlation between the Lextale-Esp score and the Spanish proficiency rating, as well as with the self-ratings of preference and frequency of use. The same pattern of correlations was observed for the number of correctly identified words, but not for the number of nonwords wrongly selected. Finally, the cognate advantage was inversely correlated with language preference. These correlations mean that participants with higher Lextale-Esp scores (and with better performance on the words) rated themselves as more proficient in Spanish. They also used more Spanish than Catalan and preferred Spanish over Catalan. Finally, the participants preferring Spanish over Catalan benefited less from the cognate status of words.

We further analyzed the patterns of correlations for Catalan-dominants and Spanish-dominants separately. Concerning Catalan-dominants, the correlations of LextaleEsp scores with Spanish proficiency remained significant. In contrast, the group of Spanish-dominants failed to show significant correlations between Lextale-Esp scores and their self-assessment ratings. This result is in line with what was reported by Izura et al. (2014), who obtained a significant correlation between those two measures only in participants who had Spanish as an L2, but not in participants who had it as their L1. According to these authors, the reason is that the Spanish L1 speakers were a very homogeneous group, all having quite high scores. Because it is difficult to find significant correlations in homogeneous datasets, this factor in all likelihood also contributed to the lack of a relationship between the objective scores and the subjective ones in our sample of Spanish-dominant bilinguals. Importantly, neither the whole group of participants nor the Catalan- or Spanishdominant participants showed any correlation between Lextale-Esp scores and self-assessment ratings of proficiency in Catalan.

In addition to studying the correlations between LextaleEsp scores and subjective ratings, we examined the differences in performance between the two groups. As can be seen in Table 1, Spanish-dominant bilinguals performed better on Lextale-Esp than did Catalan-dominant bilinguals. The statistical analyses revealed that this difference was significant, $t(154)=4.19, p<.001, d=0.7$. To know whether the difference was produced by the performance on words or on nonwords, we separately analyzed the scores for these two types of items. We observed a significant difference between the two groups of participants in the numbers of words known, $t(154)=4.41, p<.001$. In contrast, the numbers of nonwords that were incorrectly considered to be words were not different between the two groups, $t(154)=0.90, p=.36$.

Table 2 Correlations between Lextale_Esp scores and data from the language history questionnaire (all the participants)

\begin{tabular}{lllll}
\hline & Spanish Proficiency & Catalan Proficiency & Preference of Use & Frequency of Use \\
\hline Lextale_Esp total score & $.35^{*}$ & -.06 & $.32^{*}$ & $.31^{*}$ \\
Words & $.33^{*}$ & -.06 & $.30^{*}$ & $.29^{*}$ \\
Nonwords & -.14 & .02 & -.07 & -.11 \\
Cognate advantage & -.11 & .09 & -.27 & -.23 \\
\hline
\end{tabular}

${ }^{*} p<.003$ 
To examine the effect of cognate status, we ran a mixed analysis of variance on the words only. We included Cognate Status (cognate vs. noncognate) as a within-subjects factor and Group (Catalan-dominants vs. Spanish-dominants) as a between-subjects factor. The dependent variable was the percentage of words recognized. The results of this analysis revealed a main effect of cognate status, $F(1,152)=107.69$, $M S E=6,371.45, p<.001, \eta_{\mathrm{p}}{ }^{2}=.42$, with the percentage of recognized words being higher for cognates $(M=94 \%)$ than for noncognates $(M=86 \%)$. There was also a main effect of group, showing that Spanish-dominants recognized more words than did Catalan-dominants, $F(1,152)=19.01, M S E$ $=3,451.46, p<.001, \eta_{\mathrm{p}}{ }^{2}=.11$. Finally, the interaction between cognate status and group also reached statistical significance, $F(1,152)=11.66, M S E=6,371.45, p<.005, \eta_{\mathrm{p}}{ }^{2}=$ .07 . This interaction revealed that, although both Catalandominants and Spanish-dominants showed better performance with cognates than with noncognates, the advantage for cognates with respect to noncognates was larger for Catalan-dominants $(M=10.2)$ than for Spanish-dominants $(M=5.2)$.

\section{Discussion}

In this study, we examined whether Lextale-Esp scores can be used with Catalan-Spanish bilinguals. There were two reasons why this might not have been the case. First, all of the bilinguals were highly proficient in Spanish, having been raised in a fully bilingual community. Their command of Spanish thus was much better than in most of the Spanish L2 speakers tested in other studies. Second, Catalan and Spanish share a considerable number of cognates (nearly two thirds of the words used in Lextale-Esp).

As a validation criterion, we used the results of a self-rating questionnaire, asking for proficiencies in Spanish and Catalan, the relative uses of the two languages, and the preference for one language over the other. On the basis of the answers to the questionnaire, we distinguished a group of Spanish-dominant participants and a group of Catalan-dominant participants. As can be seen in Table 1, a significant difference emerged between the two groups in the numbers of Spanish words known. They did not differ in their erroneous selections of nonwords (in both groups, the percentage of false alarms was below $10 \%$, which is good). As a matter of fact, the effect size of the difference between the two groups was $d=0.7$ when based on the total Lextale-Esp scores. This is considerable, given the variability in vocabulary sizes present in both groups.

Further analysis indicated that the test could be made stronger by replacing the Catalan-Spanish cognates (Table 1). Izura et al. (2014) did not do so, because they would have had to exclude even more words, which are cognates in other languages. However, the data of our study show that if Catalan researchers wanted to make a Lextale-type test specific for Catalan research, they could do so by replacing the SpanishCatalan cognates. On the other hand, one of the reasons why Catalan people have a high proficiency in Spanish is the large overlap of the two languages. Trying to exclude this overlap might give a wrong picture of the participants' proficiency levels in Spanish.

Another interesting line of research will be to examine how Lextale-Esp scores relate to other measures of language proficiency. Correlations with self-ratings are important, but as we indicated in the introduction, are limited in a number of respects. The Lextale yes/no format is interesting because it means the test takes only 5 min to complete, and therefore can easily be integrated in experiments. Research in English has shown that the Lextale yes/no format correlates well with other tests of L2 proficiency (Harrington \& Carey, 2009; Harsch \& Hartig, 2016; Lemhöfer \& Broersma, 2012; Mochida \& Harrington, 2006). However, it would be good to run similar validation studies for Lextale-Esp.

Author note This research was funded by the Spanish Ministry of Economy and Competitiveness (Grant Nos. PSI2012-37623 and PCIN2015-165-C02-02) and by Rovira i Virgili University (Grant No. 2014PFR-URV-B2-37).

\section{References}

Abutalebi, J. (2008). Neural aspects of second language representation and language control. Acta Psychologica, 128, 466-478.

Beyersmann, E., Casalis, S., Ziegler, J. C., \& Grainger, J. (2015). Language proficiency and morpho-orthographic segmentation. Psychonomic Bulletin \& Review, 22, 1054-1061. doi:10.3758/ s13423-014-0752-9

Brysbaert, M. (2013). LEXTALE_Fr. A fast, free, and efficient test to measure language proficiency in French. Psychologica Belgica, 53, 23-37.

Bultena, S., Dijkstra, T., \& van Hell, J. G. (2014). Cognate effects in sentence context depend on word class, L2 proficiency, and task. Quarterly Journal of Experimental Psychology, 67, 1214-1241.

Christoffels, I. K., de Haan, A. M., Steenbergen, L., van den Wildenberg, W. P. M., \& Colzato, L. S. (2014). Two is better than one: Bilingual education promotes the flexible mind. Psychological Research. doi: 10.1007/s00426-014-0575-3

Conrad, M., Recio, G., \& Jacobs, A. M. (2011). The time course of emotion effects in first and second language processing: Across cultural ERP study with German-Spanish bilinguals. Frontiers in Language Sciences, 2(351), 1-16.

Cop, U., Keuleers, E., Drieghe, D., \& Duyck, W. (2015). Frequency effects in monolingual and bilingual natural reading. Psychonomic Bulletin \& Review, 22, 1216-1234. doi:10.3758/ s13423-015-0819-2

Correia, J., Formisano, E., Valente, G., Hausfeld, L., Jansma, B., \& Bonte, M. (2014). Brain-based translation: fMRI decoding of spoken words in bilinguals reveals language-independent semantic representations in anterior temporal lobe. Journal of Neuroscience, 34, $332-338$. 
Costa, A., \& Santesteban, M. (2004). Lexical access in bilingual speech production: Evidence from language switching in highly proficient bilinguals and L2 learners. Journal of Memory and Language, 50, 491-511.

Costa, A., \& Sebastián-Gallés, N. (2014). How does the bilingual experience sculpt the brain? Nature Reviews Neuroscience, 15, 336-345. doi:10.1038/nrn3709

Davis, C., Sánchez-Casas, R., García-Albea, J. E., Guasch, M., Molero, M., \& Ferré, P. (2010). Masked translation priming: Varying language experience and word type with Spanish-English bilinguals. Bilingualism: Language and Cognition, 13, 137-155.

De Bruin, A., Roelofs, A., Dijkstra, T., \& Fitzpatrick, I. (2014). Domaingeneral inhibition areas of the brain are involved in language switching: FMRI evidence from trilingual speakers. NeuroImage, 90, 348-359.

Diependaele, K., Lemhöfer, K., \& Brysbaert, M. (2013). The word frequency effect in first- and second-language word recognition: A lexical entrenchment account. Quarterly Journal of Experimental Psychology, 66, 843-863. doi:10.1080/17470218.2012.720994

Duñabeitia, J. A., Perea, M., \& Carreiras, M. (2010). Masked translation priming effects with highly proficient simultaneous bilinguals. Experimental Psychology, 57, 98-107.

Ferré, P., García, T., Fraga, I., Sánchez-Casas, R., \& Molero, M. (2010). Memory for emotional words in bilinguals: Do words have the same emotional intensity in the first and in the second language? Cognition and Emotion, 24, 760-785.

Guasch, M., Boada, R., Ferré, P., \& Sánchez-Casas, R. (2013). NIM: A Web-based Swiss Army knife to select stimuli for psycholinguistic studies. Behavior Research Methods, 45, 765-771. doi:10.3758/ s13428-012-0296-8

Harrington, M., \& Carey, M. (2009). The on-line Yes/No test as a placement tool. System, 37, 614-626.

Harsch, C., \& Hartig, J. (2016). Comparing C-tests and Yes/No vocabulary size tests as predictors of receptive language skills. Language Testing. doi:10.1177/0265532215594642. Advance online publication.

Izura, C., Cuetos, F., \& Brysbaert, M. (2014). Lextale-Esp: A test to rapidly and efficiently assess the Spanish vocabulary size. Psicológica, 35, 49-66.

Khare, V., Verma, A., Kar, B., Srinivasan, N., \& Brysbaert, M. (2013). Bilingualism and the increased attentional blink effect: Evidence that the difference between bilinguals and monolinguals generalizes to different levels of second language proficiency. Psychological Research, 77, 728-737.

Lemhöfer, K., \& Broersma, M. (2012). Introducing LexTALE: A quick and valid Lexical Test for Advanced Learners of English. Behavior Research Methods, 44, 325-343. doi:10.3758/s13428-011-0146-0
Lemhöfer, K., \& Dijkstra, T. (2004). Recognizing cognates and interlexical homographs: Effects of code similarity in languagespecific and generalized lexical decision. Memory \& Cognition, 32, 533-550. doi:10.3758/BF03195845

Lemhöfer, K., Dijkstra, T., Schriefers, H., Baayen, R. H., Grainger, J., \& Zwitserlood, P. (2008). Native language influences on word recognition in a second language: A megastudy. Journal of Experimental Psychology: Learning, Memory, and Cognition, 34, 12-31. doi:10. 1037/0278-7393.34.1.12

Levenshtein, V. I. (1966). Binary codes capable of correcting deletions, insertions, and reversals. Soviet Physics Doklady, 10, 707-710.

MacIntyre, P. D., Noels, K. A., \& Clément, R. (1997). Biases in selfratings of second language proficiency: The role of language anxiety. Language Learning, 47, 265-287.

Mochida, A., \& Harrington, M. W. (2006). The yes-no test as a measure of receptive vocabulary knowledge. Language Testing, 23, 73-98.

Moldovan, C. D., Sánchez-Casas, R., Demestre, J., \& Ferré, P. (2012). Interference effects as a function of semantic similarity in the translation recognition task in bilinguals of Catalan and Spanish. Psicológica, 33, 77-110.

Prior, A., MacWhinney, B., \& Kroll, J. F. (2007). Translation norms for English and Spanish: The role of lexical variables, word class, and L2 proficiency in negotiating translation ambiguity. Behavior Research Methods, 39, 1029-1038. doi:10.3758/ BF03193001

University of Cambridge, Local Examinations Syndicate. (2001). Quick Placement Test. Oxford, UK: Oxford University Press.

Raymond, J. E., Shapiro, K. L., \& Arnell, K. M. (1992). Temporary suppression of visual processing in an RSPV task: An attentional blink? Journal of Experimental Psychology: Human Perception and Performance, 18, 849-860. doi:10.1037/0096-1523.18.3.849

Rossi, S., Gugler, M. F., Friederici, A. D., \& Hahne, A. (2006). The impact of proficiency on syntactic second-language processing of German and Italian: Evidence from event-related potentials. Journal of Cognitive Neuroscience, 18, 2030-2048.

Van Orden, G. C. (1987). A ROWS is a ROSE: Spelling, sound, and reading. Memory \& Cognition, 15, 181-198. doi:10.3758/ BF03197716

Weber, A., Broersma, M., \& Aoyagi, M. (2011). Spoken-word recognition in foreign-accented speech by L2 listeners. Journal of Phonetics, 39, 479-791. doi:10.1016/j.wocn.2010.12.004

Zhou, H., Chen, B., Yang, M., \& Dunlap, S. (2010). Language nonselective access to phonological representations: Evidence from Chinese-English bilinguals. Quarterly Journal of Experimental Psychology, 63, 2051-2066. 